\title{
Are Disadvantaged Students Unmotivated to Read? An Interview Study of Engaged and Disengaged Readers in Low SES Australian Schools
}

\author{
Clarence Ng, Brendan Bartlett, Claire Wyatt-Smith, Janet Wyvill \\ Griffith Institute for Educational Research, Griffith University, Brisbane, Australia ${ }^{1}$
}

\begin{abstract}
This study disputed the general perception that disadvantaged students are unmotivated to read. Interviews with students in Year 5 classes at low SES schools in Queensland, Australia, provided evidence of underlying variation in the ways that engaged and disengaged readers observe and respond to their opportunities and experiences in reading at school and at home. Despite their shared disadvantaged backgrounds with disengaged readers, engaged students were more motivated to read, consistently engaged in classroom reading and often shared their reading with family members. While disengaged readers experienced motivational problems and failed to display a consistent reading engagement pattern in school and at home, most of them still considered themselves good readers and understood the importance of reading. We argue that disengaged readers were not utterly unmotivated and urge teachers to provide additional support to engage them in reading and to build on their extant reading motivation.
\end{abstract}

\section{Introduction}

Disadvantaged students are usually described as unmotivated, uninterested in and uncommitted to reading [19]. This general perception is widely shared among teachers who have worked in classrooms populated by students from diverse disadvantaged backgrounds. In a pilot investigation of this issue within a study of top-level structuring [39], teachers informed us that many such children are unmotivated and characterised by a low sense of self-efficacy, autonomy and interest in reading. We consider this perception problematic because disadvantaged students' perspectives and voices have seldom been taken into consideration in previous research on reading motivation. The current study challenged this simplistic representation by comparing two types of disadvantaged students, engaged and disengaged readers, in Australian low SES schools.
Reading comprehension is an important skill critical for academic success, future employment and personal well-being [7], [14], [15]. Recent international and national testing results in Australia indicate that disadvantaged students from culturally, linguistically and socioeconomically disadvantaged backgrounds remain disproportionally represented among those who fail to attain the minimum benchmark in reading and other literacy assessments. Further, socioeconomic disadvantage and poor literacy histories are major descriptors of youth who are disaffected, cease schooling early and fail to transition successfully into employment [4]. Typically, there are negative and enduring consequences for youth with such background, in their personal adjustment and relational futures [8], [18], [28], [29] with high rates of social offending usually with associated arrests and incarceration [10], [11], [55] and connected disadvantage to national wellbeing and economic strength. Thus, designing effective intervention to motivate disadvantaged students to read, to persist as readers, to read more and to improve their reading performance, is urgently required [1] \& [46]. Otherwise, it is likely that they will continue to fall behind and the achievement gap will widen [51].

\section{Past Studies on Reading Motivation and Engagement}

International studies on reading motivation and engagement have seldom focused specifically on disadvantaged students and have paid little attention to the contextual influences that impact reading engagement and performance for these students. This omission has left policy development, pedagogy and resourcing well-intentioned, but poorly-served by research on the nature and development conditions of disengagement amongst some low-SES students.

Motivation is critical for reading engagement because reading itself is an effortful activity that has complex semiotic and meta features [5] and typically involves deep memory processing, decision-making, preferences, choices and commitment in the pursuit of meaning-making [30], [58] and coming to value 
the activity [7]. Guthrie and Wigfield [23] defined reading motivation in terms of personal goals, values, and beliefs in reading, which aligns consistently with major cognitive explanations of motivation including expectancy-value modelling, achievement goal theory, and self-efficacy research. Collectively, these cognitive models highlight the importance of students' expectation, valuing, purposes and self-concept in reading.

Aligning with these cognitive models, reading motivation has been measured consistently with students' ratings of corresponding cognitive variables using questionnaires (e.g. Motivation to Read Profile by Gamble, Palmer, Codling and Mazzoni [20]; Reader Self-Perception Scale by Henk and Melnick [27]; Motivation for Reading Questionnaire by Baker \& Wigfield, [4]). For example, the Motivation for Reading Questionnaire (MRQ) contains a set of scales based on 11 dimensions of reading motivation (efficacy, challenge, curiosity, involvement, importance, recognition, grades, social competition, compliance, and work avoidance) which can be collapsed into cognitive variables of competence beliefs, extrinsic reasons and social purposes for reading adapted from major models of motivation [31].

Past studies have confirmed the importance of major cognitive variables, such as self-efficacy, reading interest and mastery orientation, in reading engagement and achievement. In relation to selfefficacy, the general pattern in conclusions from such research is that efficacious students persist longer in reading difficult texts, expend more effort, read more and better [12], [48], [50], [54]. Students who have developed a keen interest in reading or who are intrinsically motivated to read for enjoyment and understanding often are found to have more engaged patterns of reading behaviours including a willingness to read challenging texts. In addition, their intrinsic motivation for reading is always positively related to reading [4], [26], [54], [56] and contributes independently to reading comprehension at various levels, even after controlling for other significant factors such as past reading achievement levels [26], [54]. In addition, Guthrie and colleagues reported empirical evidence showing that students' intrinsic motivation in Year 7 relates to later reading achievement levels in Year 8 and 9 [21], [57]. More recently, reading researchers have begun to explore the significance of mastery orientations on reading performance from an achievement goal perspective. Emerging results have shown that students who have focused on mastery orientations monitor their reading process, use effective comprehension strategies, and achieve deep levels of understanding and valuing of both outcomes and processes earned and used to improve their reading [6], [9], [36], [41].

While these cognitive models have provided an empirical foundation for designing instructional interventions [38], [57], for the greater part efforts thus far to transact such knowledge into effective practice have been neither consistently effective nor readily realized for students who are at risk of reading failure or who are from disadvantaged backgrounds. Certainly, more studies are needed to help us effect better transactions, especially among those students from at risk categories and different disadvantaged backgrounds.

Thus, despite the rich empirical foundation for understanding and promoting reading engagement and achievement provided from cognitive studies on reading motivation, limited research has explored the issue of reading motivation among disadvantaged students. As mentioned earlier, few international studies have taken disadvantaged students as a specific focus. This means that we do not have a direct application from what empirical base exists that might be used to inform reformative practices to promote reading engagement and achievement where this is needed with such students. And, it is needed as classroom teachers who have worked with disadvantaged students will attest. Based on these diverse cognitive models, the important questions for the current study on disadvantaged students' personal cognitions on reading include the extent to which they consider themselves capable of reading, think of reading as important and find reading interesting and enjoyable.

Within Australia, different types or categories of disadvantage are evident in our schools, sometimes in combination. These categories apply for nonEnglish speaking backgrounds (NESB), low-SES, rural and remote geographic locations, and indigenous and other ethnic backgrounds. This profiling of diversity variables provides an opening for considering how groups of students and individual members learn to read (and how to avoid reading) within different academic, cultural, socioeconomic and physical constraints/affordances. A plethora of literacy studies has already highlighted various crippling issues such as discontinuity between home and school reading practice, the lack of economic and reading resources, and social support associated with disadvantaged students' literacy learning. These are strong indications that many disadvantaged students learn to read within a learning environment radically different from students from mainstream middle class families and schools [3], [13], [22], [35], [44], [60].

While acknowledging the importance of personal cognitions and the significant role of cognitive variables such as self-efficacy, goal setting and orientation as specific focal points, in the current study we were concerned about reading practices that these students experienced in school and at home. Our contention was that research on reading with students from low SES and other disadvantaged backgrounds needed to take into consideration the 
levels of support available to these students from teachers, peers, parents and other family members. Therefore, in this study we focused not just on students' personal cognitions on reading but also on their reading experiences in school and at home. Our report in this paper is of initial findings from a fouryear longitudinal study that investigates the development of reading engagement and avoidance among disadvantaged students in upper primary schools situated in low SES suburbs in Australia.

\section{Issues of reading among disadvantaged students}

There is a strong link worldwide between low socioeconomic status and students' low level of literacy achievement [22], [45], [48], [49]. In Australia, the 1996 National English Survey identified the reading achievement gap between disadvantaged and non-disadvantaged students [32]. One decade later, low-SES and other disadvantaged students remained disproportionally represented among those who failed to attain the minimum benchmark in reading and other literacy assessments in national literacy tests [33] \& [34]. In addition to the achievement issue, low-SES and other disadvantaged students often lack motivation to read [24]. Compared with good readers, disadvantaged students often have relatively lower level of reading efficacy, slower language development and less parental support in reading pursuits [16], [24], [43].

Barriers that disadvantaged students face in reading are exacerbated when expository texts and their required reading in different curriculum areas become more prevalent. This is routinely the case in upper primary levels and is a feature of Australian National Curriculum. Reading expository texts is a cognitively demanding feature of schooling [5]. These texts often present ideas in complex abstraction, which is a radically different format from the sequential structure students are familiar with from their wider experience of narrative texts [52] and with little deliberate, explicit signaling of the semantic and structural relationships that give texture and reader-consideration to those ideas and their communication [5], [37]. Relative to students from affluent backgrounds, disadvantaged students may have limited exposure to expository texts at home. In school, especially in early years education and in lower primary grades, teachers typically will have focused on narrative texts and have given limited attention to helping students recognise and comprehend expository texts [17]. Disadvantaged students' unfamiliarity therefore is not just with the content knowledge covered in these texts, but also with how ideas are structured within them. Undoubtedly there is high likelihood that they will find expository texts difficult to read and understand and will be more inclined to avoid engaging with such relatively inaccessible and challenging texts. In short, disadvantaged students are likely to be cognitively and motivationally under-prepared for reading in upper primary school. While it is important to note that this general description may not be true for every student coming from disadvantaged backgrounds, the persistently low levels of reading achievement among those from various disadvantaged backgrounds warrant investigation into their reading engagement process and factors that may have interfered with it.

\section{The current study}

The current study was part of a large longitudinal project on understanding reading engagement and disengagement among disadvantaged students in Australia, known as the READ project (Reading Engagement and Avoidance Development Project). It is comprised by four complementary studies involving case studies, surveys, classroom observation and intervention. In this report we have presented findings derived from the first set of interviews in the multiple case studies in which we explored the reading experiences of two groups of disadvantaged students, engaged and disengaged readers. Based on both sociocultural and cognitive theories on motivation and learning, this set of interview was constructed to gather students' insiderreports of their classroom reading experiences, home reading practices and their own personal cognitions related to reading.

\section{Method}

To understand the reading experiences of disadvantaged students that incorporated notions from the literature already presented along with encouraging additional data that insiders' views might present, we interviewed participants using a semi-structured format. Semi-structured interviews were used because they were flexible and both the interviewer and interviewee were able to raise new questions and bring up other information and responses that were personally relevant to general themes covered in the interviews, or outside those themes.

\subsection{Participants}

Participants in this study included 60 students selected from low SES schools in Queensland, Australia. At the time of writing, 46 interviews were available for analyses. The sample in this study contained 28 male and 28 female students drawn from 7 primary schools situated in low SES suburbs 
within Brisbane city and 2 others from rural Queensland, over $400 \mathrm{~km}$ away from the Brisbane CBD. The average age of these Year 5 students was 10.45 years. These students were categorized into engaged $(\mathrm{N}=22)$ and disengaged readers $(\mathrm{N}=24)$ based on teachers' evaluation.

\subsection{Procedure}

Based on the Australian Census Statistics [2], we selected a sample of schools situated in extremely low SES suburbs (lowest 5\%) in Australia. Another characteristic of these selected schools was that their students' average performance on national testing on literacy and numeracy was substantially and persistently below the national average. Using these selection criteria, we were able to access readers that had low levels of reading achievement from disadvantaged backgrounds. We then sought ethical clearance approval from Education Queensland to contact these schools and invited them to participate in the READ project. Nine schools accepted our invitation, of which, seven were situated in urban suburbs within Brisbane and two were rural schools located more than $400 \mathrm{~km}$ away north and west of Brisbane city.

To select participants from this corpus of students, we presented a bipolar scale to teachers which they used to nominate both engaged and disengaged students to take part in the multiple case study of the READ project. The bipolar scale required teachers to assess their nominees in terms of frequency of observed engagement/disengagement behaviours, levels of reading enjoyment and efficacy, purposes for reading, and willingness to take on a reading challenge. Based on teachers' nominations and their evaluation of students' reading engagement behaviours, we finalized the sets of participants for this study following parental consent for their children to join the project.

\subsection{Data collection and analyses}

The first round of the interview with these students was designed to capture students' descriptions of reading experiences in school and at home. It also explored students' personal cognitions about reading. Interview questions included:

1. About classroom reading experiences: How often do you have a reading period? What do you do during the reading period? What does your teacher usually do during the time that you read? How do you find the reading period? Tell us something that you like or dislike about the reading in this class.

2. About home reading practice: Do you read at home? What do you read? Does anyone at home read? Do you share your reading with anyone at home?
3. About personal cognitions: Is it important for you to read in this class - and why? Are you a good reader? Do you enjoy reading? Tell us a reason why you want to read or you don't want to read in this class.

The interviews were conducted in the participating schools and usually took about 30 minutes. Before starting, the interviewer explained its purpose and assured interviewees that they could refuse to answer any of the questions and that their responses would be confidential. All interviews were recorded and fully transcribed.

The analytical process involved three rounds of reading the transcripts. The first round covered all transcripts. The second round involved developing a coding system based on an intense reading of five randomly selected transcripts. The third round involved coding all transcripts using the coding system developed from the second round. Finetuning the coding system occurred simultaneously during the process of coding all the transcripts. Through this process, codes were rephrased and combined into larger themes and analytical categories.

To verify findings, these codes and themes were compared to observation notes and comments provided by the fourth author who had conducted these interviews for this project. Further verification was conducted by cross-checking students' responses from these two contrasting reader groups and teachers' initial assessment of the students' engagement characteristics.

\section{Results}

The main issue presented from these data is a comparison of the reading experiences of engaged and disengaged readers from disadvantaged backgrounds. To arrive at this output, we focused on comparing similarities and differences between these two reader groups based on their responses to the interview. The section below reports the major themes derived from this process.

Classroom reading experiences. Both groups experienced similar reading activities in school. These included a variety of reading activities such as quiet individual reading, group reading, teacher-led reading, completing worksheets, reading for promotional programs, and library reading. Everyday these two groups of students had similar opportunities to read in their class time. In terms of the range and choice of reading materials, both groups had a personal choice of books selected from their classroom and library collections. In general, these two groups of readers had similar reading experiences in school.

The major difference between them was their perceptions of teacher activities when they were 
asked to read in their classes. Forty-five percent $(\mathrm{N}=10)$ of the engaged readers reported that their teachers read with them, offered assistance and continued to work with them. In contrast, only $13 \%$ $(\mathrm{N}=3)$ of the disengaged readers had similar perceptions, that is, perceptions that their teachers interacted with them with the intention of helping them read during their reading sessions. Rather, most disengaged readers $(46 \%, \mathrm{~N}=11)$ reported that teachers spent their time on disciplining students or working on their own personal matters such as taking a snack or talking to another teacher when students were reading, or were unsure about what their teachers did $(25 \%, \mathrm{~N}=6)$.

In response to probes of what they liked about the reading lessons, $86 \%(\mathrm{~N}=19)$ of the engaged readers identified different intrinsic aspects of reading lessons such as having opportunities to read different types of books. While a majority of disengaged readers $(58 \%, \mathrm{~N}=14)$ also raised intrinsic aspects, $23 \%(\mathrm{~N}=5)$ explained that they liked their reading lessons for extrinsic reasons, such as having a chance to sit with friends. In terms of what they disliked, most engaged readers $(32 \%, \mathrm{~N}=7)$ quoted, "being interrupted", while more disengaged readers $(38 \%$, $\mathrm{N}=9$ ) spoke to what they saw as a tedium in reading, calling it "boring" or regretting the "need to do it every day".

Home reading practice. As expected, some disengaged readers $(29 \%, \mathrm{~N}=7)$ did not read at home. However, a majority of both engaged $(82 \%, \mathrm{~N}=18)$ and disengaged readers $(67 \%, \mathrm{~N}=16)$ reported that they did. Nevertheless, these two groups of readers did not have similar home reading experiences. Most engaged readers $(86 \%, \mathrm{~N}=19)$ own their books while a majority of disengaged readers $(46 \%, \mathrm{~N}=11)$ did not, and needed to borrow from the library. Compared to disengaged readers $(46 \%, \mathrm{~N}=11)$, many engaged readers $(68 \%, \mathrm{~N}=15)$ had access to other reading materials such as newspapers and magazines. More importantly, more engaged readers $(41 \%, \mathrm{~N}=9)$ than disengaged readers $(17 \%, \mathrm{~N}=4)$ reported that they would read these materials.

In terms of reading practice of family members, a higher proportion of engaged readers reported that their parents read $(73 \%, \mathrm{~N}=16)$ and shared reading (64\%, N=14) with them than did the disengaged readers (Parents read 59\%, N=13; Parent shared reading $32 \%, \mathrm{~N}=7$ ). Another important finding about home reading practice was that many engaged readers $(64 \%, \mathrm{~N}=14)$ reported that their siblings read. In contrast, relatively few disengaged readers $(25 \%, \mathrm{~N}=6)$ indicated this reading practice at home. In terms of encouragement, most disengaged readers reported that their parents encouraged them to read. However, this parental encouragement was often presented to them in the form of verbal instruction.

In terms of using computing technologies to do their reading at home, both groups reported that they had access to computer and internet. While more disengaged readers said they used emails and Facebook than did their counterparts, both groups reported that they did not use them often.

Personal cognitions. As expected, there were only a few $(9 \%, \mathrm{~N}=2)$ engaged readers who did not consider themselves as good readers, while seven of the disengaged readers $(29 \%, \mathrm{~N}=7)$ described themselves in such negative manner. In terms of labeling themselves as good readers, surprisingly, a similar number of engaged and disengaged readers rated themselves as a "good reader" $(45 \%, \mathrm{~N}=10$ for engaged readers; $46 \%, \mathrm{~N}=11$ for disengaged readers) or "kind of a good reader" ( $41 \%, \mathrm{~N}=9$ for engaged readers; $25 \%, \mathrm{~N}=6$ for disengaged readers).

While more engaged readers $(86 \%, \mathrm{~N}=19)$ than disengaged readers $(63 \%, \mathrm{~N}=15)$ reported that they enjoyed reading, both unanimously considered reading important.

Regarding their reasons for engaging in reading, engaged readers mainly cited intrinsic reasons $(81 \%$, $\mathrm{N}=18$ ) such as interesting books, exciting stories, learning something new to explain why they wanted to read. Few engaged readers $(18 \%, \mathrm{~N}=4)$ quoted extrinsic reasons.

Every engaged reader was able to find a reason to read. In contrast, 38\% ( $\mathrm{N}=9)$ disengaged readers reported that they did not have a reason to read. Only $46 \%(\mathrm{~N}=11)$ of them quoted intrinsic reasons to explain their reading engagement.

In terms of their reasons for disengaging from reading, a similar percentage of readers from both groups $(18 \%, \mathrm{~N}=4$ for engaged readers; $21 \%, \mathrm{~N}=5$ for disengaged readers) quoted external reasons such as "being interrupted" to explain why they did not read. Only one mentioned boredom as a reason for reading disengagement. In contrast, $25 \%(\mathrm{~N}=6)$ of disengaged readers mentioned boredom. Quite a few $(27 \%, N=6)$ engaged readers reported that they could not find a reason to disengage from reading.

Another major difference between these two groups was the activities that they volunteered they would substitute for reading. Compared to disengaged readers $(29 \%, \mathrm{~N}=7)$, more engaged readers $(55 \%, \mathrm{~N}=12)$ reported that they would find constructive and academic work to do if they did not feel like reading. Few $(19 \%, \mathrm{~N}=4)$ indicated that they would engage in non-academic activities when they did not feel like reading. In contrast, most disengaged readers said they would spend their time on games or just being bored $(64 \%, \mathrm{~N}=14)$.

\section{Discussion}

This interview study helped us to examine the reading experiences, home reading practice, and personal cognitions related to reading of a cohort of Year 5 Australian students in low SES schools. Based on teachers' assessment, both engaged and 
disengaged readers were selected for this study. Regardless of the commonality of their low SES backgrounds, all were exposed to similar reading education and reading experiences in school. Their accounts of school reading experiences presented an identical picture of reading education characterized by a variety of reading activities, daily reading exercises and similar reading materials.

These two groups had different perceptions of teacher interaction during reading periods. A majority of engaged readers felt that their teachers cared about them and worked with them while most disengaged readers considered differently - notably, that their teachers worked on other activities including disciplining students or abrogated any responsibility to interact with them. It should be noted that in our design, both engaged and disengaged readers were drawn from the same classrooms. The contrasting perceptions from their emic viewpoints indicate the importance of understanding students' reading experiences from their own perspectives. While it is possible that these students (both engaged and disengaged readers) may have distorted their observations or made inaccurate interpretations about teachers' behaviours, this finding indicates that it is important to understand students' perspectives and the factors that may have influenced their classroom perceptions.

Another major finding was that the students' home reading experiences were dependent on several factors including access to different reading materials, parental reading practices and more importantly siblings' reading practice. Previous research already has highlighted the importance of reading resources and parental involvement in promoting reading at home [3], [31], [44]. Our study added a new finding to the reading research literature in that siblings' reading practice may be important familial influences that previous research on reading has not been able to explore sufficiently. Our engaged readers reported that their siblings read with them, shared reading materials, and taught younger siblings to read.

At a personal level, it was surprising to find that both engaged and disengaged readers considered reading important. During the course of interviewing, we had adapted our questions and repeatedly asked students to confirm whether they considered reading important. All but two students confirmed their positive replies. This finding was not in line with teachers' initial assessment of disengaged readers. It provided a basis for reviewing current characterisations of disengaged readers in the literature [19], [24]. Further, emerging findings suggest disengaged readers' perceptions that reading is important may be a learned rhetoric. According to our observation, most failed to maintain a pattern of reading behaviours consistent with their assertions that reading is important for them.
Another unexpected finding was that a majority of disengaged readers described themselves as good readers. This finding may indicate that they have not been able yet to develop a realistically differentiated view about themselves currently as readers. There may be some advantage in not having done so, in that their self-efficacy may still be open to formative and constructive influence. Given this possibility, it is feasible that through their teachers' support and scaffolding of fun, adventure and knowledge in reading experiences, they might build positively on this undifferentiated conception.

Based on the interview findings, this study has provided empirical evidence that disputed the generality that disadvantaged students are unmotivated to read. The results showed that most engaged readers considered themselves capable of reading, enjoyed reading in school, understood the importance of reading and why they had to read, participated in all sorts of reading activities in their class. At home, most engaged readers own books, had access to other reading materials, though seldom chose to read them, and most importantly, read with their parents or siblings.

Based on the interview responses, it can be concluded that most engaged readers were cognitively prepared for, equipped and engaged in reading in school. While it was not clear about the level of reading support they received from family members, most engaged readers reported they read at home. The findings about engaged readers were, of course, limited by the self-report responses. Our observations and engagement with these readers in their schools provided verification to their interview responses. In addition, teachers' evaluation and nominations confirmed that these engaged readers were indeed motivated to read.

As for disengaged readers, it can be concluded that most of them were not keen readers. While they considered reading important and rated themselves as good readers, not many of them understood why they needed to read and often experienced negative emotion when reading in school. Contrary to the engaged group, most readers did not read at home and had limited reading supports from their parents and other family members. From a cognitive perspective, it can be said that these disengaged readers suffered from deficiencies in intrinsic reading motivation and other positive forms of reading motivation, though most of them rated their reading confidence high and considered reading important. Their teachers also considered them disengaged in reading. However, we were reluctant to label them as utterly unmotivated because most offered some positive responses- talking about books they enjoyed reading, or considering themselves as good readers or reading for both intrinsic and extrinsic reasons. Our observation of these disengaged readers recorded moments and situations 
in school where they were totally engaged, which could be found, for example, when they were reading their favourite books, using computer to read, and totally immersed in the seas of books in the school library [40].

It can be concluded that these disengaged readers had experienced some motivational problems in reading in school. They were not consistently motivated to read and their perception that reading is important was not reflected correspondently in their reading behaviours. However, they were engaged in reading situations and events that met their needs and preferences. Certainly, more support is required from teachers to understand them and find effective ways to support their reading engagement and build their motivation to more authentically positive levels.

\section{Conclusion}

In conclusion, this study showed that there were important differences between engaged and disengaged readers in their home reading experiences, perceptions about teacher behaviours, and their reasons for engaging in and disengaging from reading. Notwithstanding that these two groups of readers were drawn from similar disadvantaged backgrounds, their responses indicate a contrasting pattern of reading engagement and motivation. Taken together, the interview results remind us of the missed opportunities as educators in taking disadvantaged students as a generic group. More research is required to look into the development of reading behaviours among these two groups of readers and understand how various social influences including those derived from teachers, peers and family members may have influenced their reading engagement patterns. While there is limitation to what we can do to change the family reading environment and practices for disadvantaged students, school teachers should examine critically their classroom practices and improve their understandings of disadvantaged students' reading. In particular, there is a need to observe, understand, and interact with students in different reading contexts and to listen to their own accounts of themselves as readers in order to develop a more accurate representation of their needs, preferences and strengths in reading [19]. Such critical reflection cannot be complete without a thorough consideration of disadvantaged students' perceptions of adequacy of teacher support in classroom reading [40].

\section{References}

[1] Alexander K.L., Entwisle D.R., and Olsen, L.S. (2001) 'Schools, achievement, and inequality: A seasonal perspective', Educational Evaluation and Policy Analysis 23, pp.171-191.
[2] Australian Bureau of Statistics (2006) 'Socio-economic Indexes for Areas (SEIFA)',

http://www.abs.gov.au/AUSSTATS/abs@.nsf/Lookup/203

3.0.55.001Main+Features12006?OpenDocument March 2011).

[3] Baker, L. (2003) 'The role of parents in motivating struggling readers', Reading and Writing Quarterly 19(1), pp. 87-106.

[4] Baker, L. \& Wigfield, A. (1999) 'Dimensions of Children's Motivation for Reading and Their Relations to Reading Activity and Reading Achievement', Reading Research Quarterly 34(4), pp.452-477.

[5] Bartlett, B. J. (2010) 'Learning about written language, literacy and meaning: A metalinguistic gift', in M. Raich, P. Schober, \& J. Zelger (Eds.), Linguistic Structures, Theory and Practice, Studien Verlag: Innsbruck, pp.47-64.

[6] Bartlett, B. J. (2012) 'New perceptions, renewed orientation and positive valuing: The power in children's learning about how ideas connect', in P. Schober, J. Zelger, \& M. Raich, (Eds.), GABEK V. Werte in Organisationen und Gesellschaft. Values in Organizations and Society, Studien Verlag: Innsbruck, pp.353-372.

[7] Bartlett, B. J. (2012) Reconnecting disaffected youth through successful transition to work project. Report to BoysTown, Griffith University, Brisbane.

[8] Behrens, M. \& Evans, K. (2002) 'Taking control of their lives? A comparison of the experiences of unemployed young adults (18-25) in England and the New Germany', Comparative Education 38(1), pp.17-37.

[9] Botsas, G. \& Padeliadu, S. (2003) 'Goal orientation and reading comprehension strategy use among students with and without reading difficulties', International Journal of Educational Research 39, pp. 477-495.

[10] Carter, E. W. \& Lunsford, L. B. (2005) 'Meaningful work: Improving employment outcomes for transition-age youth with emotional and behavioural disorders', Preventing School Failure 49(2), pp.63-69.

[11] Carter, E. W. \& Wehby, J. H. (2003) 'Job performance of transition-age youth with emotional and behavioral disorders', Exceptional Children 69, pp.449465 .

[12] Chapman J. W. \& Tunmer, W. E. (1995) 'Development of young children's self-concepts: An examination of emerging sub-components and their relationship with reading achievement', Journal of Educational Psychology 87(1), pp.154-167.

[13] Comber, B. Badger, L. Barnett, J. Nixon, H. \& Pitt, J. (2002) 'Literacy after the early years: A longitudinal study', Australian Journal of Language and Literacy 25(2), pp. 9-23.

[14] Desjardines, R. (2004) Learning for well-being: Studies using international adult literacy survey. Institute of International Education, Stockholm University, Stockholm, Sweden. 
[15] DeWalt, P. \& Pignone, M. (2005) 'Reading is fundamental: The relationship between literacy and health', Archives of Internal Medicine 165(17), pp.19431944.

[16] Dickinson, D.K. (1991) Bridges to literacy: Children, families, and schools, Blackwell Press, New York.

[17] Duke, N.K. \& Pearson, P.D. (2002) 'Effective practices for developing reading comprehension', in A. E. Farstrup \& S. J. Samuels (Eds.), What research has to say about reading instruction, International Reading Association: Newark, pp. 205-242.

[18] Dwyer, P. (2004) 'Agency, 'dependency' and welfare: beyond issues of claim and contribution?', in H. Dean (Ed.), The ethics of welfare: Human rights, dependency and responsibility, The Policy Press: Bristol, pp. 135-154.

[19] Edmunds, K. M. \& Bauserman, K. L. (2006) 'What teachers can learn about reading motivation through conversation with children', The Reading Teacher 59, pp.414-424.

[20] Gamble, L. B., Palmer, B. M., Codling, R. M. \& Mazzoni, S. A. (1996) 'Assessing motivation to read', The Reading Teacher 49, pp.518-533.

[21] Gottfried, A. E., Fleming, J. S., \& Gottfried, A. W. (2001) 'Continuity of academic intrinsic motivation from childhood through late adolescence: A longitudinal study', Journal of Educational Psychology 93, pp. 3-13.

[22] Greene, A., \& Anyon, J. (2010) 'Urban school reform, family support, and student achievement' Reading and Writing Quarterly 26, pp.223-236.

[23] Guthrie, J. T., \& Wigfield, A. (2004) 'Engagement and motivation in reading', in M. L. Kamil, P. B. Mosenthal, P. D. Pearson \& R. Barr (Eds.), Handbook of reading research, Erlbaum: Mahwah, NJ, pp. 403-422.

[24] Guthrie, J. T., Coddington, C. S., \& Wigfield, A. (2009) 'Profiles of reading motivation among African American and Caucasian students', Journal of Literacy Research 41, pp.317-353.

[25] Guthrie, J. T., Hoa, A. L. W., Wigfield, A., Tonks, S. M., Humenick, N. M., \& Littles, E. (2007) 'Reading motivation and reading comprehension growth in the later elementary years', Contemporary Educational Psychology, 32 , pp. 282-313

[26] Guthrie, J. T., Wigfield, A., Metsala, J. L., \& Cox, K. E. (1999). 'Motivational and cognitive predictors of text comprehension and reading amount', Scientific Studies of Reading 3, pp. 231-256.

[27] Henk, W. A., \& Melnick, S. A. (1995) 'The Reader Self-Perception Scale (RSPS): A new tool for measuring how children feel about themselves as readers', The Reading Teacher 48(6), pp. 470-482.

[28] Henman, P. (2002) 'Deconstructing welfare dependency: The case of Australian welfare reform', Radical Statistics 79/80, pp. 7-17.
[29] Karpur, A., Clark, H. B., Caproni, P., \& Sterner, H. (2005) 'Transition to adult roles for students with emotional/behavioral disturbances: A follow-up study of student exiters from Steps-to-Success', Career Development for Exceptional Individuals 28(1), pp.36-46.

[30] Kintsch, W. \& van Dijk, T. A. (1978) 'Toward a model of text comprehension and production', Psychological Review 85, pp.363-394.

[31] Klauda, S.L. (2009) 'The role of parents in adolescents' reading motivation and activity', Educational Psychology Review 21(4), pp.325-363.

[32] Masters, G. N. \& Forster, M. (1997) Mapping literacy achievement. Results of the 1996 National School Literacy Survey, Department of Education, Training and Youth Affairs, Canberra.

[33] MCEECDYA (2008) National report: Achievement in reading, writing, language conventions and numeracy 2008, Ministerial Council for Education, Early Childhood Development and Youth Affairs, Canberra.

[34] MCEECDYA, (2009) National report: Achievement in reading, writing, language conventions and numeracy 2009, Ministerial Council for Education, Early Childhood Development and Youth Affairs, Canberra.

[35] McCarthey, S. I. (1997) 'Connecting home and school literacy practices in classrooms with diverse populations', Journal of Literacy Research 29, pp. 145-182.

[36] Meece, J. L. \& Miller, S. D. (2001) 'A longitudinal analysis of elementary school students' achievement goals in literacy activities', Contemporary Educational Psychology 26, pp. 454-480.

[37] Meyer, B. J. F., Wijekumar, K., Middlemiss, W., Higley, K., Lei, P-W., Meier, C. \& Spielvogel, J. (2010) 'Web-based tutoring of the structure strategy with or without elaborated feedback or choice for fifth- and seventh-grade readers', Reading Research Quarterly 45(1), pp.62-92.

[38] Miller, S. D. \& Meece, J. L. (1997) 'Enhancing elementary students' motivation to read and write: A classroom intervention study', Journal of Educational Research 97, pp. 286-300.

[39] Ng, C., Bartlett, B. J., Chester, I. \& Kersland, S. (in press) 'Improving reading performance for economicallydisadvantaged students: Combining strategy instruction and motivational support', Reading Psychology.

[40] Ng, C. \& Bartlett, B. J. (in press) Case studies of disadvantaged students' reading motivation: Avoiding a deficit perspective, in Education in Australia: Cultural Influences, Global Perspectives and Social Challenges, Hauppauge, NY: Nova Publisher.

[41] Nolen, S. B. (2007) 'Young children's motivation to read and write: Development in social contexts', Cognition and Instruction 25(2), pp. 219-270. 
[42] Olsen, C.B. (2011) The reading/writing connection: Strategies for teaching and learning in the Secondary Classroom (3rd ed.), Allyn \& Bacon, Boston.

[43] Pan, B., Rowe, M., Singer, J., \& Snow, C. (2005) 'Maternal correlates of growth in toddler vocabulary production in low-income families', Child Development 76, pp.763-782.

[44] Rennie, J. (2006) 'Meeting kids at the school gate: The literacy and numeracy practices of a remote indigenous community', Australian Educational Researcher 33(3), pp. 123-142.

[45] Rothman, S. \& McMillan, J. (2003) Influences on achievement in literacy and numeracy (LSAY Research Report No.36), Australian Council of Educational Research.

[46] Schacter, J. \& Jo, B. 'Learning when school is not in session: A reading summer day-camp intervention to improve the achievement of exiting First-Grade students who are economically disadvantaged', Journal of Research in Reading 28(2), pp.158-169.

[47] Schunk, D. H. 'Self-efficacy for reading and writing: Influence of modeling, goal setting, and self-evaluation', Reading and Writing Quarterly 19, pp. 159-172.

[48] Sirin, S. R. (2005) 'Socioeconomic status and academic achievement: A meta-analytic review of research', Review of Educational Research 75, pp. 417453.

[49] Snow, C.E. \& Biancarosa, G. (2003) Adolescent literacy and the achievement gap: What do we know and where do we go from here? Carnegie Corporation, New York.

[50] Solheim, O. J. (2011) 'The impact of reading selfefficacy and task value on reading comprehension scores in different item formats', Reading Psychology 32(1), pp. $1-27$.

[51] Stanovich, K. (1986) 'Matthew effects in reading: Some consequences of individual differences in the acquisition of literacy', Reading Research Quarterly 21, pp.360-407.

[52] Stein, N.L. and Trabasso, T. (1981) 'What's in a story: An approach to comprehension and instruction', in R. Glaser (Ed.), Advances in instructional psychology (Vol. 2), Erlbaum: Hillsdale, N.J., pp.213-267.

[53] Sweet, A. P., Guthrie, J. T. \& Ng, M. M. (1998) 'Teacher perceptions and student reading motivation', Journal of Educational Psychology 90(2), pp. 210-223.

[54] Taboada, A., Tonks, S., Wigfield, A., \& Guthrie, J. (2009) 'Effects of motivational and cognitive variables on reading comprehension', Reading and Writing 22, pp. 85106.

[55] Traub, F. \& Weisstein, F. E. (2010). Disconnected Young Adults in New England: Understanding the Challenge, Quincy, MA: Nellie Mae Education
Foundation.; www.nmefdn.org/uploads/DYAReport_NellieMae_JuneFI NAL.doc (11 August 2012).

[56] Unrau, N. \& Schlackman, J. (2006) 'Motivation and its relationship with reading achievement in an urban middle school', Journal of Educational Research 100, pp. 81-101.

[57] Wang, J. H. \& Guthrie, J. T. (2004) 'Modeling the effects of intrinsic motivation, extrinsic motivation, amount of reading, and past reading achievement on text comprehension between U.S. and Chinese students', Reading Research Quarterly 39, pp.162-186.

[58] Wigfield, A., Guthrie, J. T., Tonks, S., \& Perencevich, K. C. (2004) 'Children's motivation for reading: Domain specificity and instructional influences', Journal of Educational Research 97, pp. 299-311.

[59] Woods, A. (2012) 'What Would Socially-Just Literacy Instruction Look Like?', in R. Henderson (Ed.), Teaching literacies in the middle years, Oxford University Press: South Melbourne, pp190-207.

[60] Wyatt-Smith, C. M., \& Bridges, S. (2008) Meeting in the middle assessment, pedagogy, learning and students at educational disadvantage. Final Evaluation Report for the Department of Education, Science and Training on Literacy and Numeracy in the Middle years of Schooling, DEEWR, Canberra. 